\section{All you need to know about $\mathbf{H}-2$}

\section{Hilliard Festenstein}

Biology of the Mouse Histocompatibility-2 Complex: Principles of Immunogenetics Applied to a single system. By Jan Klein. Pp. xii +620. (Springer: Berlin and New York, 1975.) DM97.60; $\$ 42$.

DURING the past decade, the science of immunogenetics as applied to the major histocompatibility system, previously regarded as a somewhat esoteric area of scientific endeavour, has come into its own. Its rate of development has been unprecedented and it has provided new insight into such diverse biological problems as transplantation and cancer immunology at one end of the spectrum to those which are not even immunological at all--like hormonal control and the genetics of infertility-at the other end of the spectrum. It represents the key to the understanding of antigen recognition, cell interaction, embryonic development and differentiation, and processes involved in the pathogenesis and manifestation of a variety of diseases. It has become important not only for the basic scientist but also for clinicians-. rheumatologists, neurologists, nephrologists, obstetricians, endocrinologists, to mention but a few.

The major histocompatibility system is the most complex and polymorphic system geneticists have had to cope with and the more that is known about it, the more important it seems to become. Jan Klein's exhaustive treatise on the immunogenetics of $\mathrm{H}-2$ is thus a very welcome and timely arrival. It starts with an introduction dealing with the history of transplantation immunogenetics and the geneology and origin of the inbred and congenic laboratory mouse strains; there follow detailed descriptions of the methods and the current status of $\mathrm{H}-2$ serology. In the section dealing with histocompatibility, there is a short introduction to transplantation immunology followed by a discussion on the methods of histocompatibility testing and effects, comparing those of the $\mathrm{H}-2$ system with various others-the erythrocyte (Ea) alloantigen loci, Ly, virusassociated alloantigen loci and non- $\mathrm{H}-2$ histocompatibility loci.

The section on the principles of genetic analysis, recombination and mutation in the H-2 complex and the genetics of the $\mathrm{H}-2$ linked loci will be of particular value to those researchers entering the field; it contains a clear account of the genetic terminology and approach basic to an understanding of this science. There is also a comprehensive section on the biochemistry of the $\mathrm{H}-2$ gene products. The book is reasonably up to date and even includes discussions on the recently discovered complement gene in $\mathrm{H}-2$ and the $\mathrm{Ia}$ specificities, as well as the newly described $X$ locus. It ends with a short speculative chapter on the function and evolution of the $\mathrm{H}-2$ complex; and there is a chronological table of the major events in the history of the $\mathrm{H}-2$ system which is interesting and puts the author's own contributions into perspective. The references are an invaluable part of this book and will provide researchers with a rapid and comprehensive list of the major publications in this fascinating and new field.

This book will probably find a place on the shelf of every laboratory seriously engaged in the study of immunogenetics.

\section{Indispensible guide to tropical pollution}

\section{M. Yonge}

Tropical Marine Pollution. (Elsevier Oceanography Series, 12.) Edited by E. J. Ferguson-Wood and R. E. Johannes. Pp. ix +192 . (Elsevier Scientific: Amsterdam, Oxford and New York, 1975.) Dfl.65; \$26.95.

WE may be grateful for the original idea of the late E. J. Ferguson-Wood resulting in the production of this book under the final editorship of $R$. E. Johannes, who is also responsible for writing much the most important sections.

Although temperate seas have been the initial sufferers from pollution, the basically more susceptible tropical waters are all too rapidly becoming similarly afflicted. And what may be effective preventive measures in the former regions may not be applicable in the tropics. In so many different ways involving chemical and physical characters, community structure and biological processes, responses to pollution in the tropics differ significantly from those in temperate waters.

The second and longest chapter comprises the fullest available study of pollution and degradation of coral reef communities. Writing with a great wealth of experience, Dr Johannes covers every aspect of the problem from the effects of sedimentation to those of dredging, from those of bad land management to those of sugar mill discharge and of sewage outflow, the latter so dramatically demonstrated at Kaneohe Bay to the north of Honolulu where I once collected from immaculate reefs. He finally discusses effects of oil and thermal pollution, and those of abnormal salinities. These last are produced by desalination plants, an analysis by R. H. Chesher of the impact of one at Key West forming the final chapter.

What is known about the impact of man on mangroves-it is estimated that some of those defoliated during the Vietnam war may take a century to recover-is succinctly reviewed by W. E. Odum and R. E. Johannes. There is a most useful account by J. C. Zieman of the effect of pollution on tropical eel grass communities, aptly described as "nurseries, food producers and stabilisers of the sea floor." The same author also collaborated with Ferguson-Wood in a description of the effects of thermal pollution by a power station most unsuitably sited in Biscayne Bay, Florida and involving the destruction of both sea grass beds and mangroves.

Although there is much of value in all chapters, those contributed by $\mathrm{Dr}$ Johannes are of over-riding importance greatly enhanced by his personally assembled list of references occupying 28 pages. This is a short and expensive book but is contains a wealth of information valuable to all, but surely indispensable to those confronted by the almost daily growing problems of pollution in tropical seas.

\section{Multidisciplinary approach to pollution}

\section{N. W. Moore}

Pollutants and Animals: A Factual Perspective. By F. Moriarty. Pp. 140. (Allen and Unwin: London, September 1975.) $£ 5.65$.

THIS short book is a lucid account of the facts which have to be taken into account by those who study the effects of pollutants on living organisms. Probably more is known about the pollution effects of the organochlorine insecticides than any other chemical group, and so Dr Moriarty uses the organochlorines as the example on which to base his pertinent conclusions. About $80 \%$ of the book is about these compounds and the chemically related polychlorobiphenyls (PCBs), the remaining $20 \%$ being devoted to the effects of heavy metals, and a brief general review of pollution in air, water and on land. Radioisotopes are covered in two pages. At first sight the subject matter of the book seems unbalanced, but the advantages of using the organo- 